\title{
\#Matine 003: The Man Who Knew Infinity
}

\author{
Matematik ve Matematik Mühendisliği Topluluğu ${ }^{1}$ \\ ${ }^{1}$ Affiliation not available
}

November 26, 2020

Gerçek hayattan uyarlanan filmlerin kurgu olanlara nispeten daha etkileyici oldukların söyleyebiliriz. Benzer hayatlarımız olmasa bile izlediğimiz bu hayatları örnek almak ve onlardan ders çıarabilmek mümkün. MMMT olarak bu içeriğimizde Hintli Matematikçi Srinivasa Ramanujan'ın hayat hikayesinin anlatıldığ Sonsuzluk Teorisi veya orijinal ismiyle The Man Who Knew Infinity filmini inceleyeceğiz. Hem kendi sinırlarını hem de matematiğin sınırlarını zorlayan bir matematikçinin hayat hikayesini matematikçi bakış açısıyla iz-

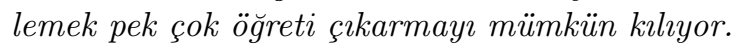

\section{"Doğru biçimde ifade edilen matematik, sadece gerçeği değil aynı zamanda ilahi güzelliği de haizdir."}

Bertrand Russel

SPOILER Yazımız filmdeki olaylara dair bilgiler içermektedir.

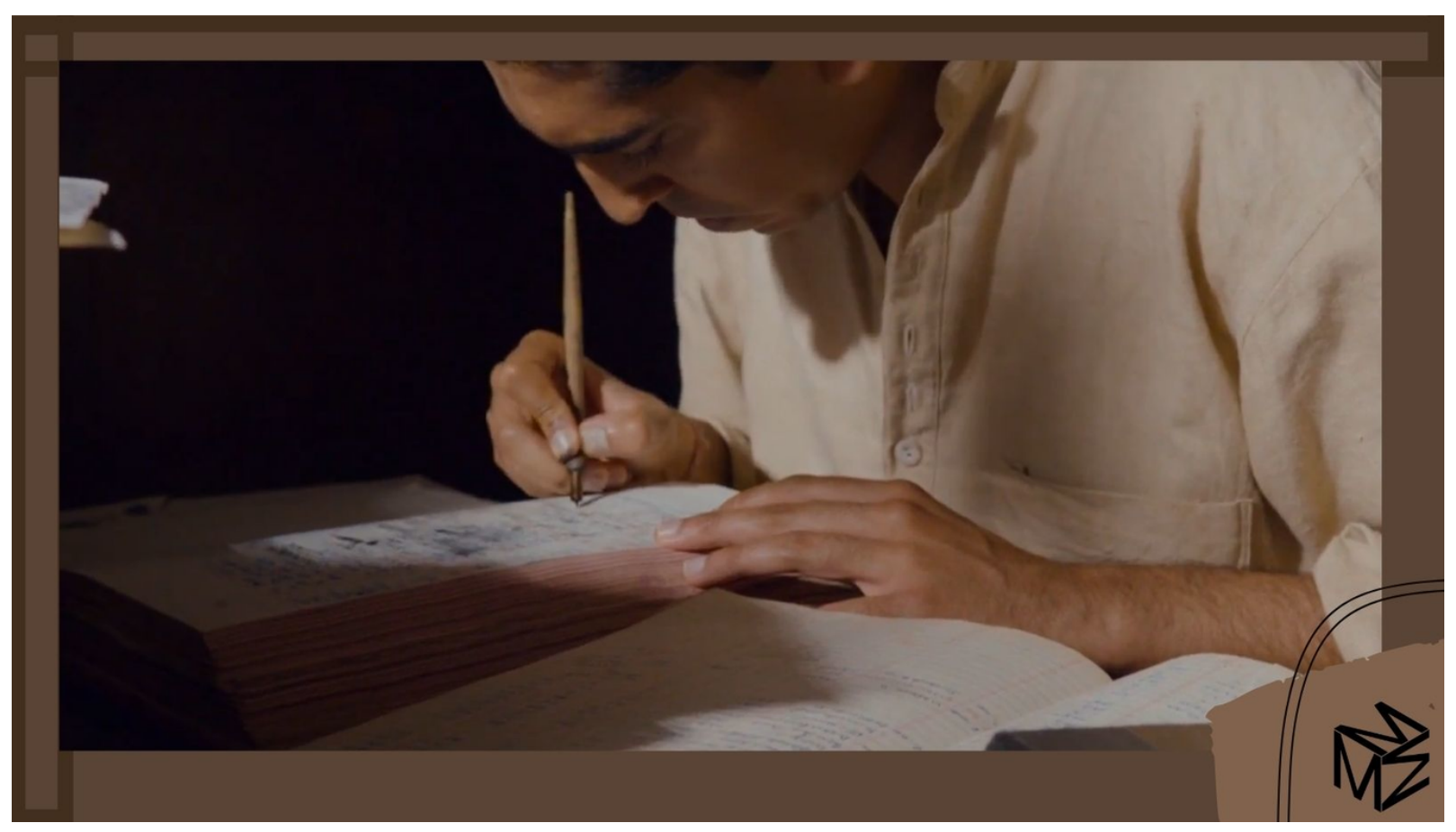

Hindistan'ın güneyinde geçim sıkıntısı içinde yaşayan Ramanujan diploması olmadı̆̆ı için iş bulmakta güçlük çeker, elinde teoremlerinin bulunduğu defterle kapı kapı dolaşıp zor da olsa bir iş bulur ve teoremleri üzerinde çalışmalarına devam eder. Ramanujan'ın matematiğe bakış açısını eşiyle aralarında geçen bir 
konuşmadan anlayabiliriz. Eşinin teoremler için;

"Ben de anlamak istiyorum. Göremediğim renkler olarak kalmasını istemiyorum."

demesi üzerine Ramanujan matematiği anlamanın elimizdeki bir avuç kumun her tanesini yakından görebilmeye benzetir.

"Her şeyde bir motif var. Işı̆̆ın renklerinde, su üzerindeki yansımalarda... Matematik ilminde bu motifler en ihtişaml şekillerde tecelli ediyorlar."

diyerek sözlerine devam eder. Ramanujan'ın bu benzetmesini doğadaki altın oran örnekleriyle destekleyebiliriz; deniz kabuğu, kozalak, girdap, ayçiçeği, örümcek ağı... Etrafımızdaki neredeyse her ögede bir motif, o motifin ardında ise matematik vardır. Görebilmek içinse tek ihtiyacımız olan matematiğin dilini anlayabilmektir.

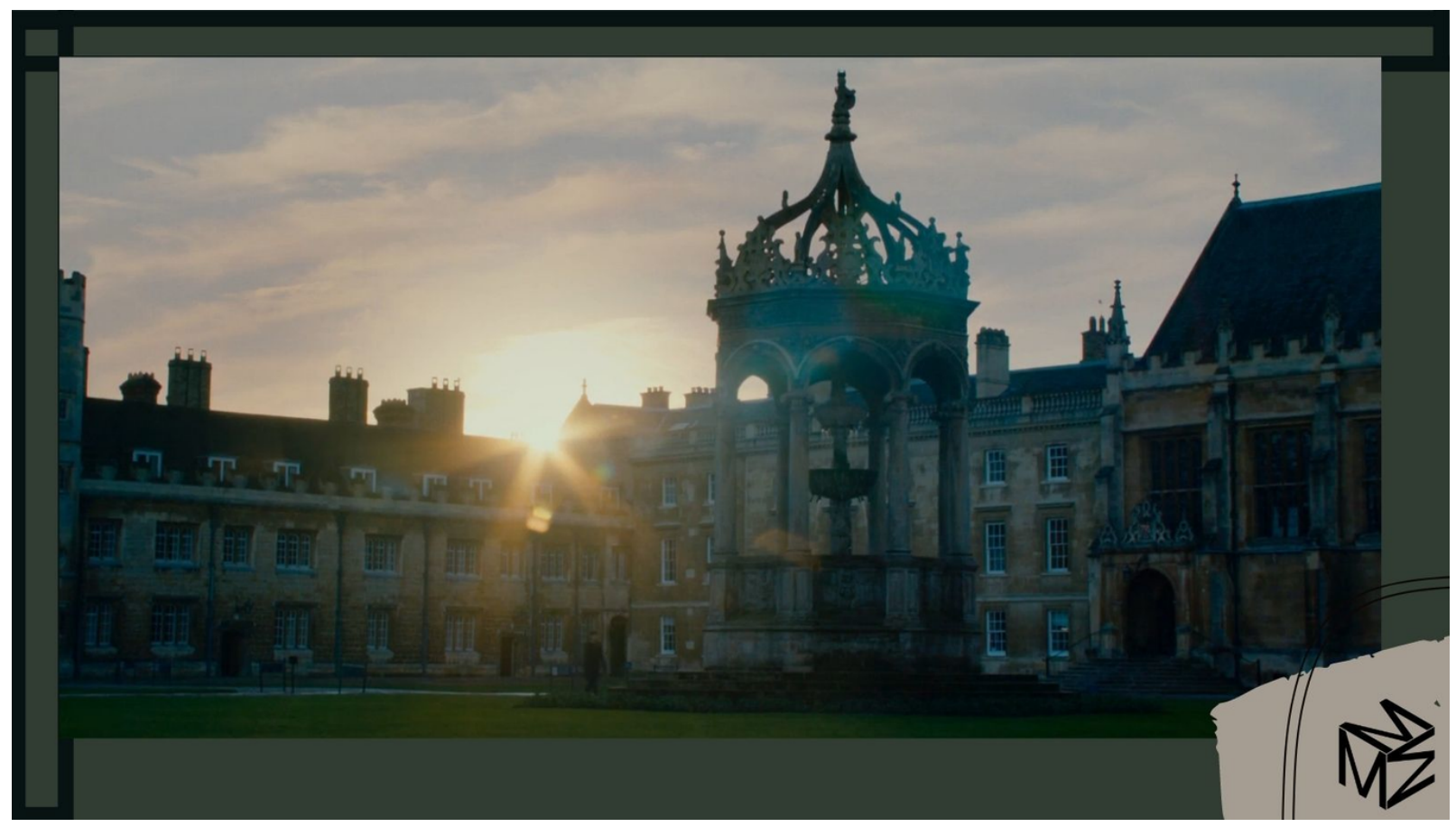

Ramanujan matematiğe belki benim penceremden bakan birileri vardır diye düşünür ve İngiliz patronunun aracılığıyla Cambridge Üniversitesi'nde Matematik Profesörü Hardy'e teoremlerini gönderir. Ramanujan ilk olarak "sonsuz bir seride X'ten küçük kaç adet asal sayı olduğunu kesin olarak hesaplamayı sağlayan bir fonksiyon" geliştirdiğini öne sürer. Ancak bu teoremin ispatları olmadığı için kabul edilmez. Matematikte sezgiler asla yeterli değildir, yaptıklarınız açıklanabilir ve ispatlanabilir olmalıdır. Çünkü matematik sadece doğru veya yanlışla ilgilenmez, neden doğru veya yanlış olduğunu da açıklamalıdır. Matematik, ispattan bağımsız düşünülemez. Filmde, Profesör Hardy bu konuyla ilgili Ramanujan'a şu sözleri söyler;

"Tıpkı Mozart'ın koca bir senfoniyi zihninde işitebilmesi gibi sen de sayılarla sonsuzluğa doğru raks ediyorsun. Fakat bu raks, bu sanat; bizleri birer hokkabaz olarak gören güruha kendimizi sevdirmek için pek faydalı olamıyor. O yüzden matematiğin gayet iyi işleyen alanlarına meydan okumaya cüret edersek hata yapma ihtimalini göze alamayız." 


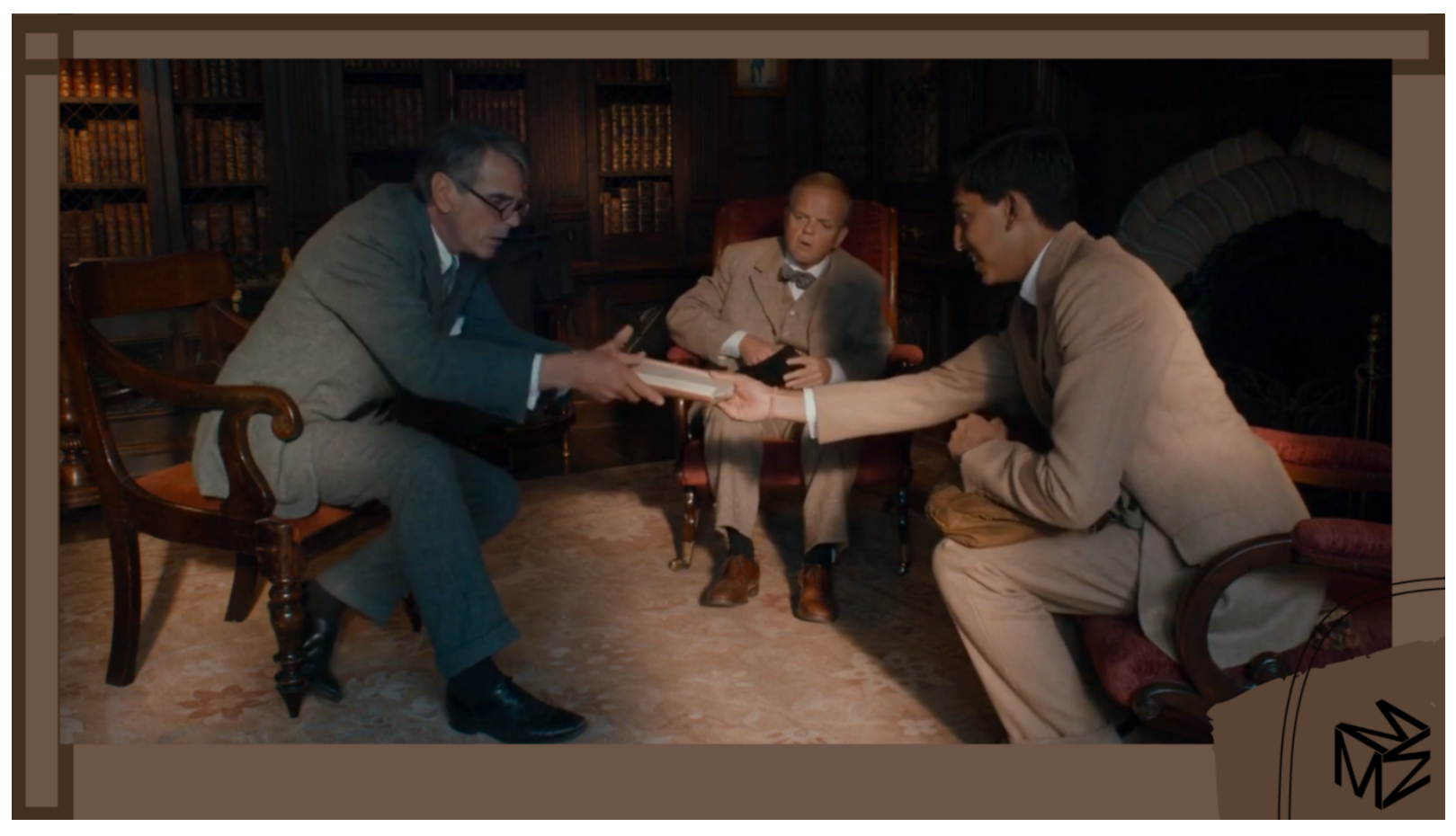

Prof. Hardy'nin Ramanujan'dan istediği Tanrı'nın kulağına fısıldadığını iddia ettiği teoremleri ispatlamasıdır. Ramanujan ise ispatlamaya gerek olmadığını teoremlerin sezgileri doğrultusunda doğru olduğunu düşünür.

Filmde Newton'ın "Principia Mathematica” eserinin görülmeye değer olduğundan bahsedilir. Newton'un matematiksel çalışmaların fiziksel yanını, Ramanujan'ın notlarınınsa soyut yanını temsil ettiğine değinilir. Newton'un ispatlanması ve anlaşılması çok uzun sürdüğü için Ramanujan'ın teoremlerini ispatlamasının aynı zamanda onun anlaşılmasını da să̆layacağından önemli olduğu vurgulanabilir. 


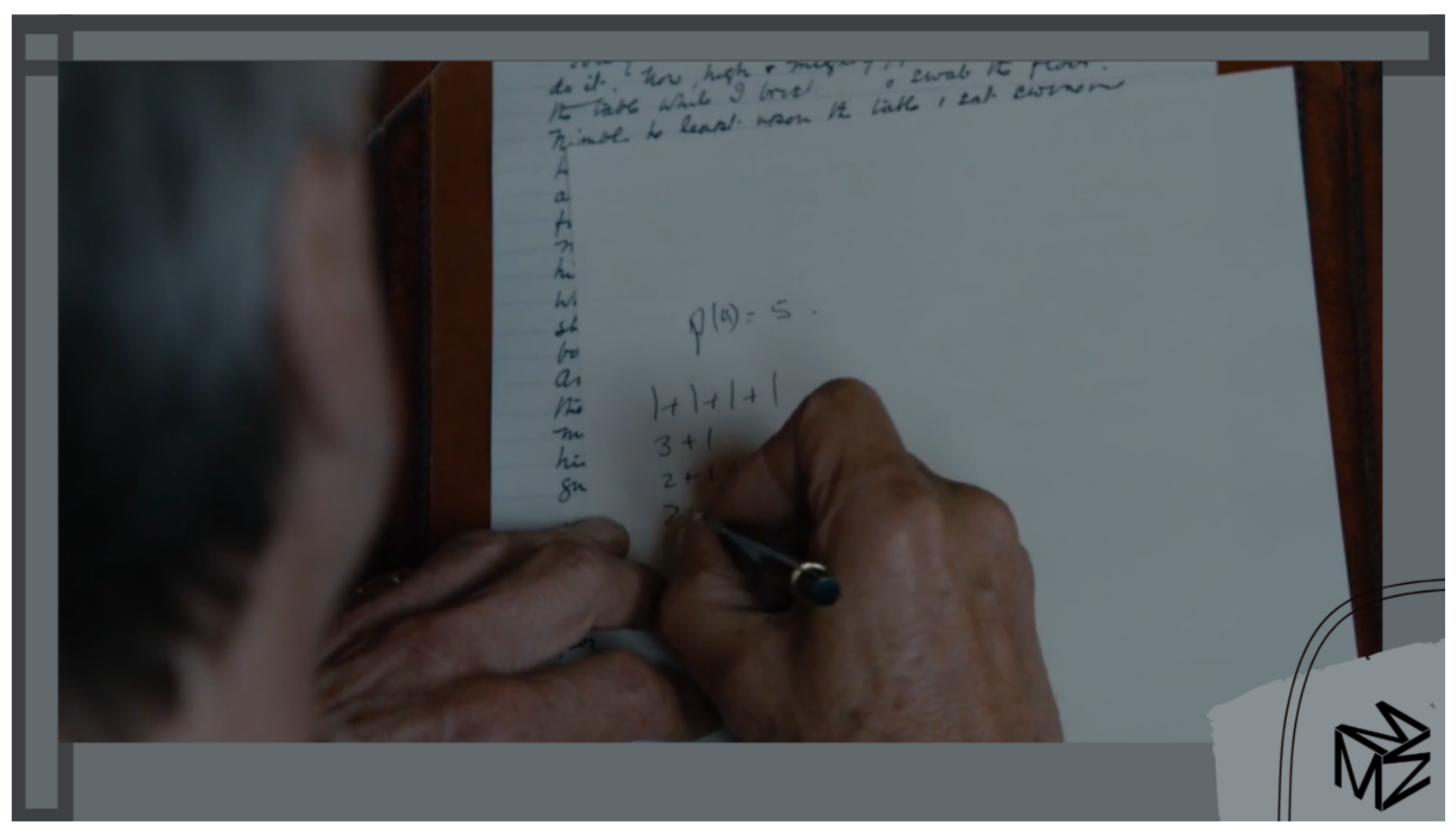

Filmde gösterilen Ramanujan'ın bir diğer teoremi ise "Bölüntüler "ile ilgilidir. Teoremi filmde gösterildiği gibi açıklayalım;

$P^{4}=5$ bunun anlamı 4 rakamını bulmanın 5 yolu var demektir:

$1+1+1+1,2+1+1,2+2,3+1$ ve 4.

Eğer P'yi 100 yaparsak 240226 faklı kombinasyon oluyor. Tüm bu kombinasyonu tek tek hesaplamak haftalar sürerken Ramanujan'ın bulduğu formülde istediğimiz sayıyı yazdı̆̆ımızda bölüntüler çıkıyor. Profesör Hardy bu teoremi hatalı bulup şu sözlerle ifade ediyor;

"Kendi başına dahice olsa da aslında yanlış. Gerçek asal sayılardan daha azını tahmin ediyor, daha fazlasının değil. Asal sayı yaklaşımını gerçek asal sayılarla karşılaştırırsan hesap sonucu daima daha yükse ğe hareket eder. Her ne kadar sezgiyle açıkmış gibi görünse de konu hesaplamaya geldiğinde başarısız oluyor."

Ramanujan sezgilerine inanarak doğru olduğunu düşündüğü teoremlerin hatalı olmasına karşı çıkar ve büyük bir hırsla ispatlamak için çalışır. Ramanujan bu çalışmalarıyla matematikte ispatın gerekliliğini de kabul etmiş olur. 


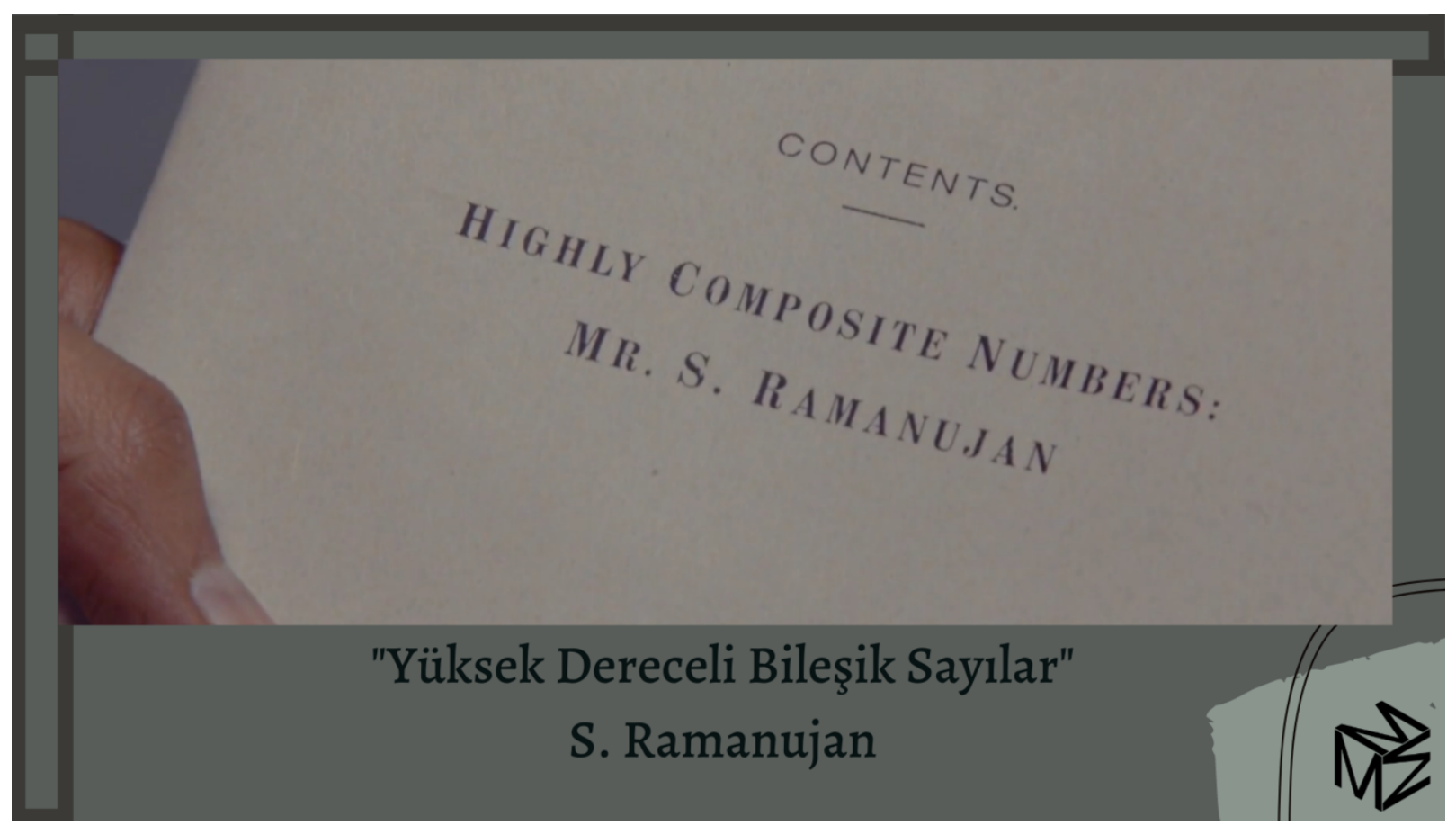

Ramanujan bu teorem üzerine çalıştı̆̆ı sırada Londra Matematik Topluluğu'nda Yüksek Dereceli Bileşik Sayılar makalesi yayınlanıyor.

Profesör Hardy ve Ramanujan bölüntüler ile ilgili teoremi üzerinde hata payını azaltma çalışmalarına devam ettikleri süreçte Ramanujan verem hastalığına yakalanıyor ancak

"Teoremlerim benimle beraber mezara gitmemeli."

diyerek çalışmalarına devam ediyor. \%0.004'lük dilimin içine girerek teoremi ispatllyorlar ve Ramanujan Kraliyet Topluluk Üyesi olmayı başarıyor. Bundan bir sene sonra ise hastalığı ilerlediği için vefat ediyor. 


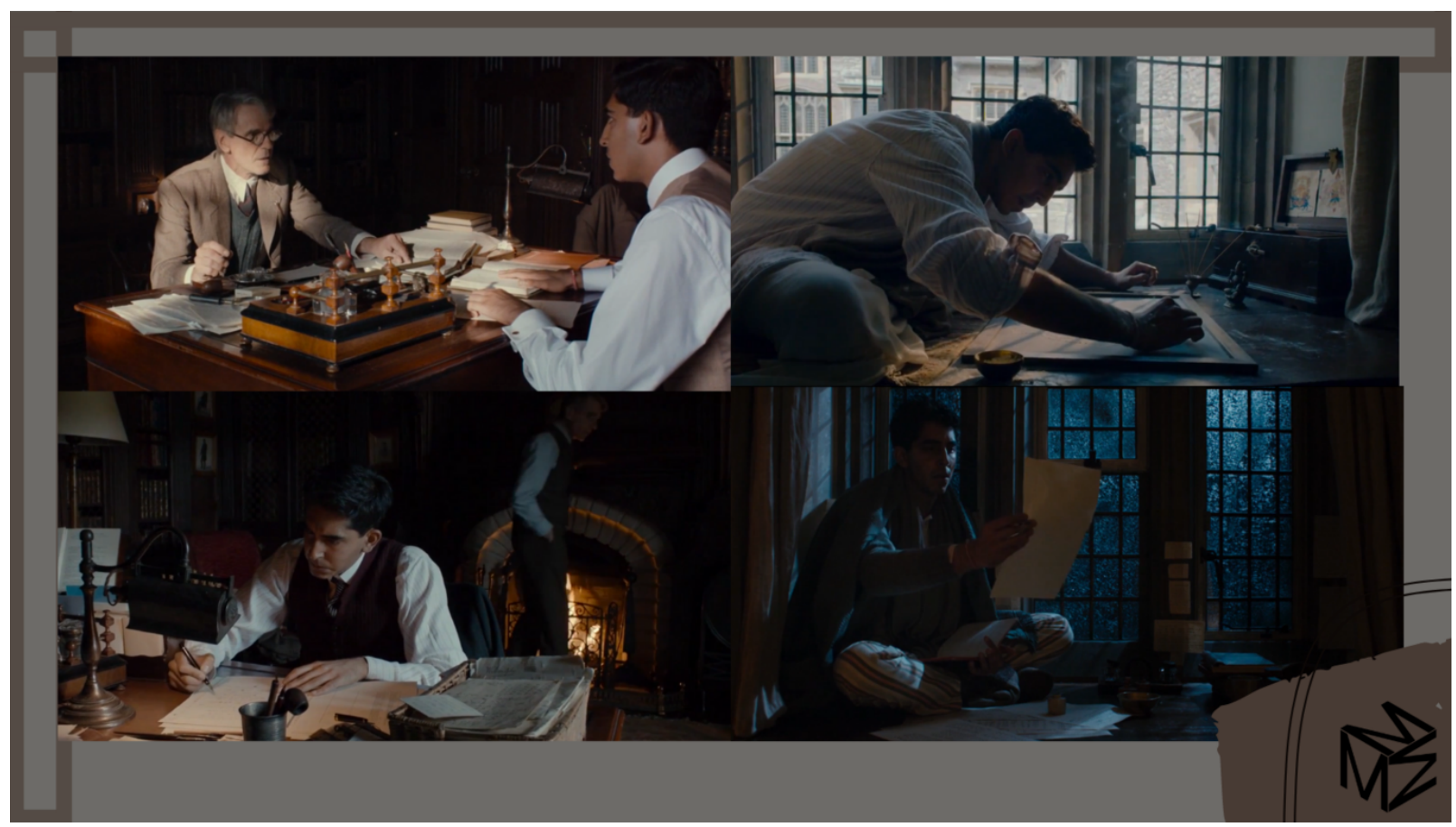

1976'da Ramanujan'ın hayatının son yılını kapsayan çı̆̆ır açıcı yeni formüllerinin bulunduğu kayıp not defteri bulundu. Önemi Beethoven'ın 10. Senfonisi ile karşılaştırılacak kadar büyüktü. Bir asır sonra bu formüller kara deliklerin davranışlarını anlamakta kullanıldı. Ramanujan'ın korktuğu gibi teoremleri onunla birlikte mezara gitmedi. Hardy ile birlikte geçirdikleri beş yıl boyunca yaptıkları çalışmalar ve elde ettiği başarılar nesiller boyunca matematikçileri etkilemeye devam ediyor.

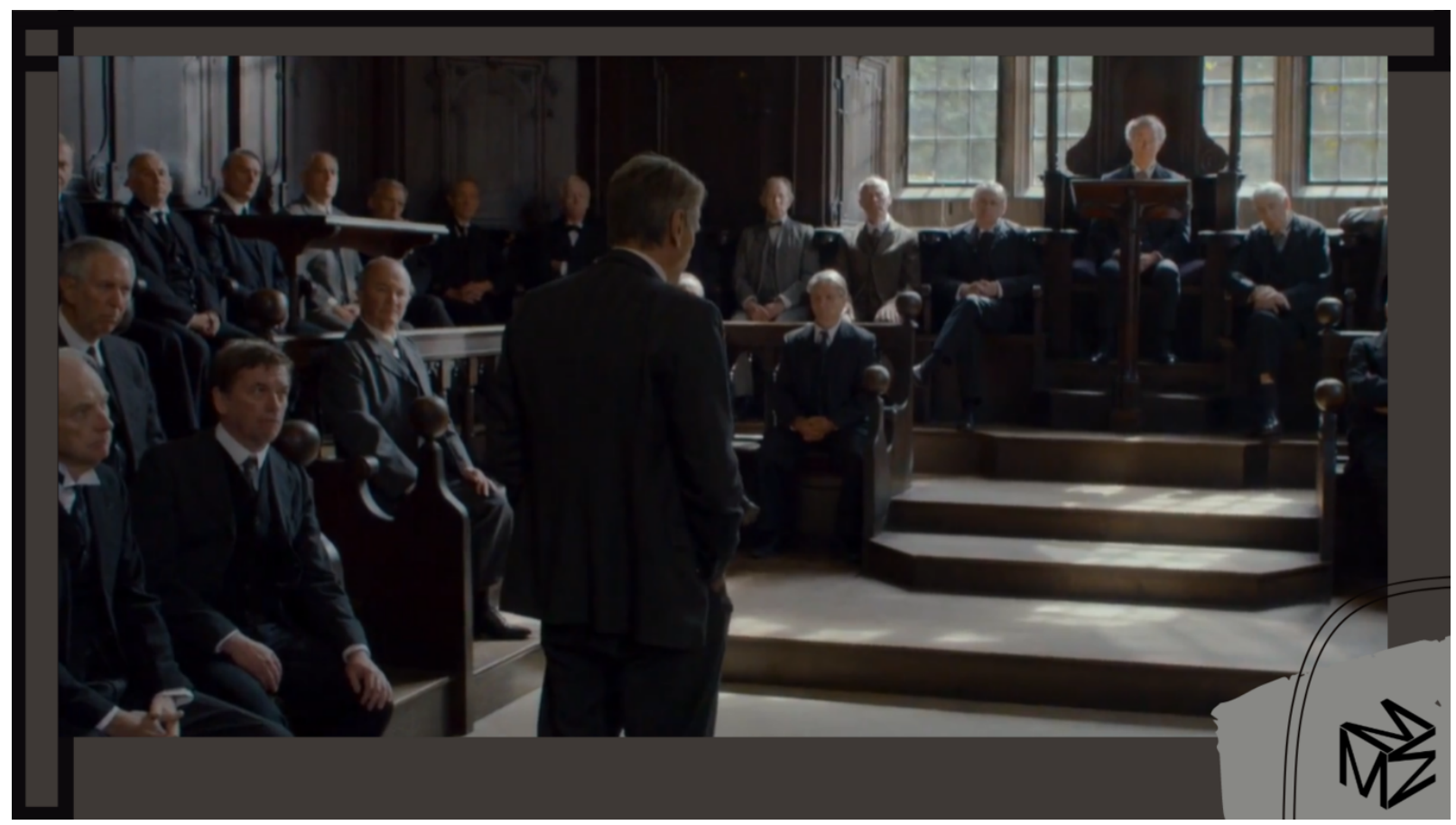




\section{Srinivasa Ramanujan hakkında ilginç gerçekler}

- Srinivasa Ramanujan'ın matematiğe olan ilgisi bir kitapla başladı. Ünlü bir matematikçi tarafından yazılmamıştı ve güncel çalışmalarla da dolu değildi. Kitap, George Shoobridge Carr tarafından yazılmış, Saf ve Uygulamalı Matematikte Temel Sonuçların Bir Özeti'ydi (1880, 1886'da revize edildi). Kitapta kanıtsız olarak sunulmuş binlerce teorem vardı ve Ramanujan'ın ilgisini çeken de kanıtlarının olmamasiydi.

- Ramanujan matematikte bir dahi olmasına rağmen, kariyerine iyi bir başlangıç yapamadı. 1904'te üniversiteye burs kazandı, ancak matematik dışındaki konularda başarısız olunca kaybetti. Madras'taki (günümüzde Chennai) kolejde bir başka deneme de, İlk Sanatlar Sınavı'nda başarısız oldu. Bu sıralarda ünlü defterlerine başladı.

- Ramanujan, Cambridge Üniversitesi'nde profesörlere tanıtım mektupları yazmaya başladı. İlk iki mektubu cevapsız kaldı, ancak üçüncü mektubu - 16 Ocak 1913'te G.H. Hardy'e - hedefini vurdu.

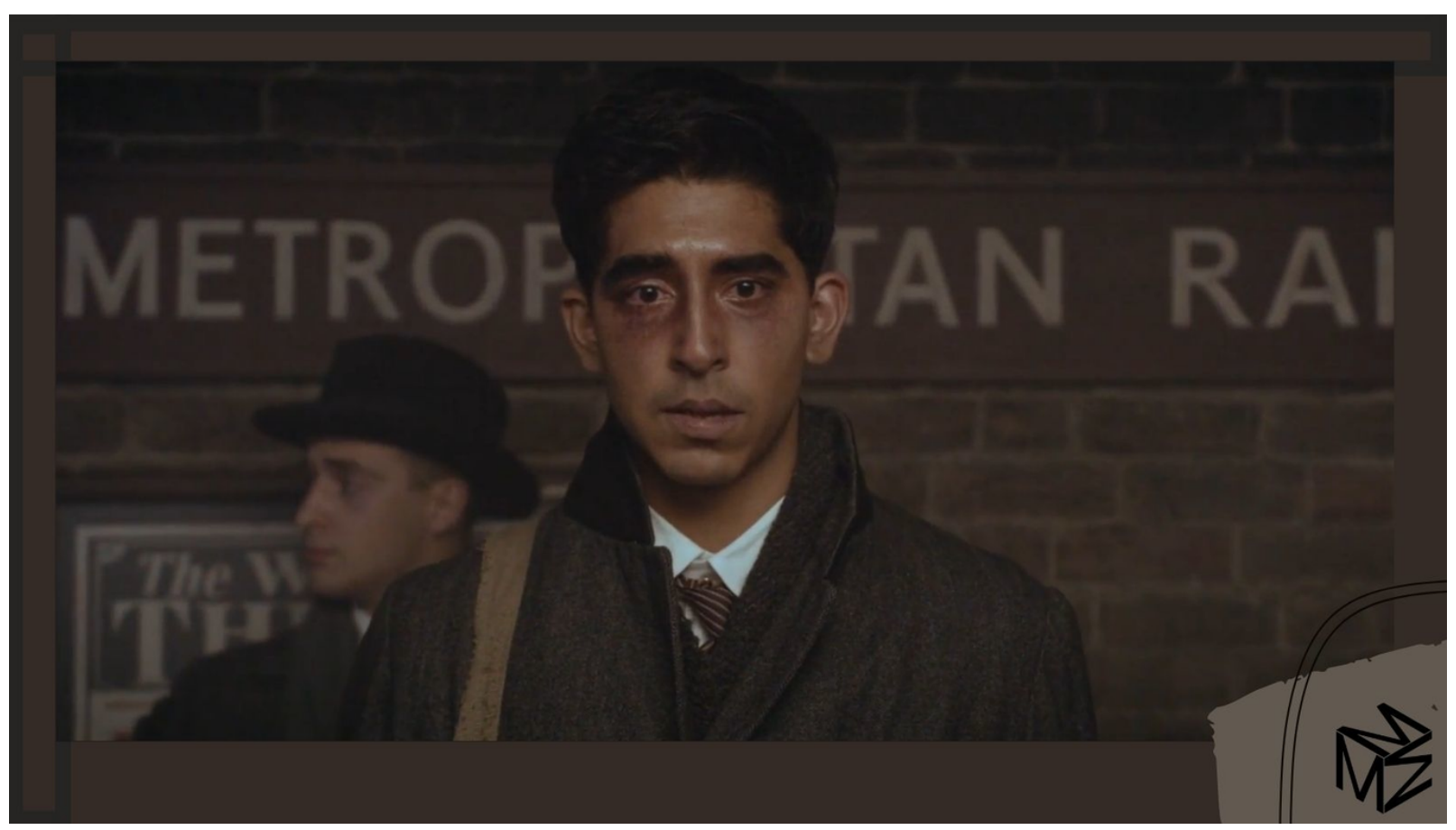

- Meşhur bir anekdotta Hardy, Ramanujan'ı ziyaret etmek için bir taksiye bindi. Oraya vardığında Ra-

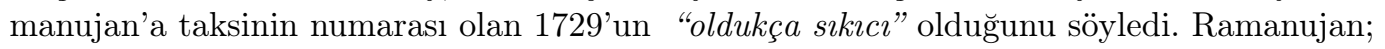

"Hayır, çok ilginç bir sayı. İki küpün iki farklı şekilde toplamı olarak ifade edilebilen en küçük sayıdır. Yani, $1729=1^{3}+12^{3}=9^{3}+10^{3}$."

Bu sayı artık Hardy-Ramanujan Sayısı olarak adlandırılıyor ve iki küpün n farklı şekilde toplamı olarak ifade edilebilen en küçük sayılara taksi numaraları deniliyor. İki küpün üç farklı şekilde toplamı olarak ifade edilebilecek en küçük sayı 87.539.319'dur.

- Hardy, 0'dan 100'e giden bir matematik yeteneği ölçeği buldu. Kendini 25'e koydu. Büyük Alman matematikçi David Hilbert 80, Ramanujan ise 100'deydi.

- Ramanujan, 1920'de 32 yaşında öldüğünde, Ramanujan geride üç defter ve bir deste kă̆ıt (Kayıp Defter) bıraktı. Bu defterler, onlarca yıl sonra hala matematiksel çalışmaya ilham veren binlerce sonuç içeriyordu. 


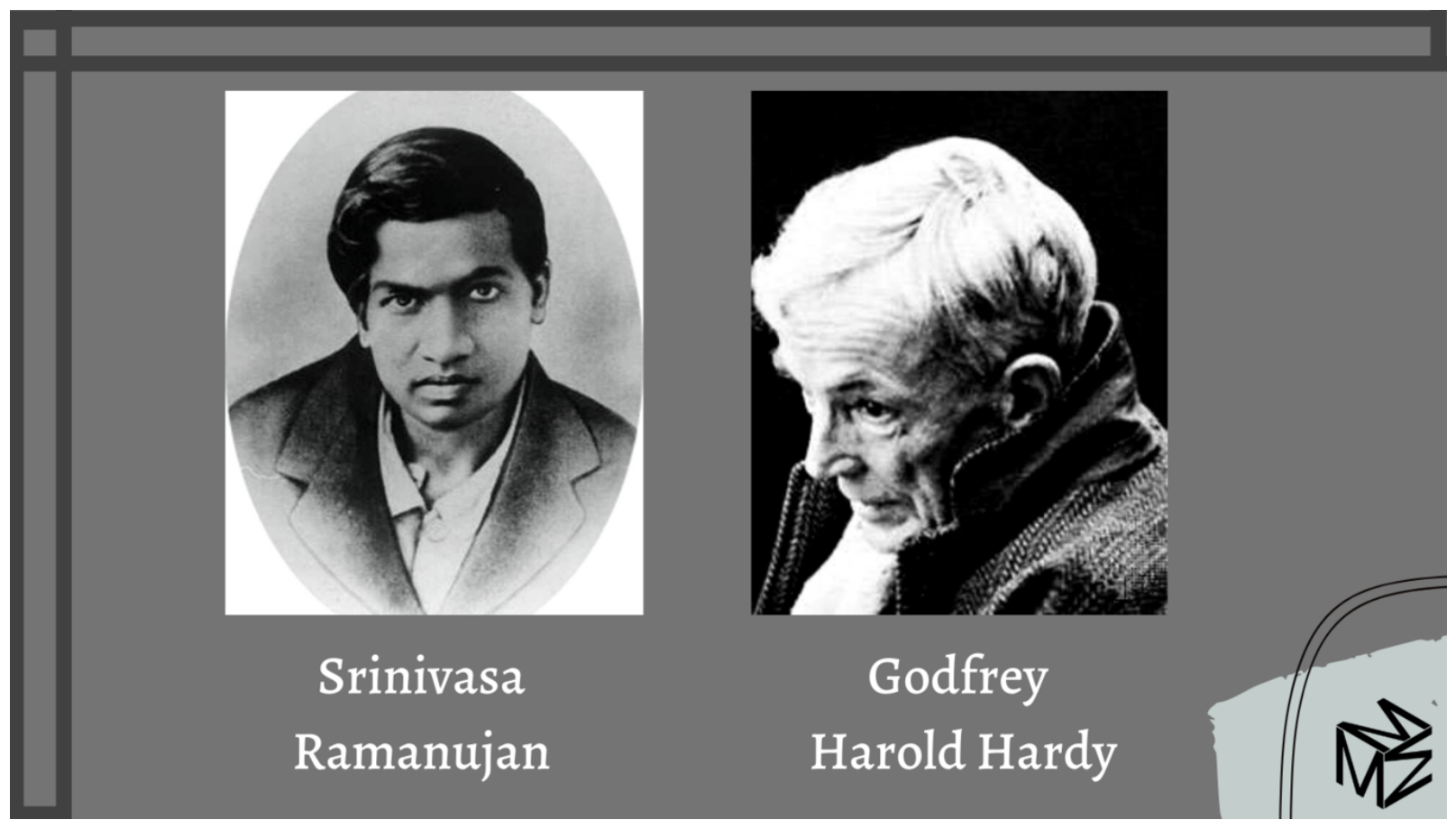

\section{Godfrey Harold Hardy}

G.H. Hardy, tam ismiyle Godfrey Harold Hardy, (d. 7 Şubat 1877, Cranleigh, Surrey , İngiltere - 1 Aralık 1947, Cambridge , Cambridgeshire), çalı̧̧maları esas olarak analiz ve sayı teorisi olan önde gelen İngiliz saf matematikçidir. Hardy; Cambridge'deki Trinity College'dan 1899'da mezun oldu, 1900'de Trinity'de öğretim üyesi oldu ve burada 1906'dan 1919'a kadar matematik dersleri verdi. 1912'de Hardy ve John E.Littlewood; Diophantine Analizi Teorisi, ıraksak seriler toplamı, Fourier Serileri dahil olmak üzere matematikteki birçok alana temelde katkıda bulunan bir makale serisinin ilki olan Riemann Zeta Fonksiyonu ve asalların dağılımı ile ilgili makaleler yayınladılar. Hardy ve Littlewood arasındaki işbirliği, 20. yüzyıl matematiğinde çok ünlüdür. Hardy, 300'den fazla bildiri ve 11 kitabın yazarı veya ortak yazarıydı. 10 baskıya giren ve üniversite öğretimini dönüştüren Saf Matematik Kursu (1908), Littlewood ile Eşitsizlikler (1934), EM Wright ile Sayılar Teorisi (1938) ve Divergent Series (1948). Matematikçilerin nasıl düşündüğüne dair tamamen kişisel bir açıklama sunan Bir Matematikçinin Özürü (1940) geniş çapta okunmaya devam ediyor. Royal Society üyesi (1910) ve London Mathematical Society (1926-28, 1939-41) başkanı seçilerek çalışmaları için büyük bir onur kazandı .

MMMT olarak Sonsuzluk Teorisi filmini sizler için inceledik. Filmi izlemeyi ve yorumlarınızı sosyal medya hesaplarımızdan bizlerle paylaşmayı unutmayın!

MMMT olarak Matine serimizde incelediğimiz bir diğer film için tıkla:

\#Matine 002: A Beatiful Mind

Yazımıza atıfta bulunmak için aşağıdaki gibi APA formatını kullanabilirsiniz: 
MMMT. (2020, Kasim 16). \#Matine 003: The Man Who Knew Infinity. -erişim tarihi- tarihinde, https://www.authorea.com/users/328187/articles/492920-matine-003-the-man-who-knewinfinity?access_token $=\mathrm{uCj6Xk7LxZKv3F2DWqzYUg}$ adresinden erişildi.

\section{Referanslar}

[1] Britannica. (t.y.). Interesting Facts About Srinivasa Ramanujan. 15 Kasım 2020

tarihinde, https://www.britannica.com/story/interesting-facts-about-srinivasa-

ramanujan adresinden erişildi.

[2] Britannica. (t.y.). Godfrey Harold Hardy. 15 Kasım 2020

tarihinde, https://www . britannica.com/biography/Godfrey-Harold-Hardy adresinde erişildi. 